\title{
Resident Preferences for Program Director Role in Wellness Management
}

\author{
Russ C. Kolarik, MD ${ }^{1,2}$, Richard L. O'Neal, MD', and Joseph A. Ewing, MS ${ }^{4}$ \\ 'University of South Carolina Greenville, Greenville, SC, USA; ${ }^{2}$ Combined Internal Medicine and Pediatrics Residency, Greenville Health System/USC \\ SOM Greenville, Greenville, SC, USA; ${ }^{3}$ University of Kentucky Markey Cancer Center, Lexington, KY, USA; ${ }^{4}$ Quality Management Department, \\ Greenville Health System, Greenville, SC, USA.
}

BACKGROUND: Burnout and depression are prevalent among resident physicians, though the supportive role of the program director (PD) is not well defined.

OBJECTIVE: To understand the residents' view of the residency program director's role in assessing and promoting resident wellness.

METHODS: A single institution survey of all house staff was conducted in 2017. Rates of burnout and depression were identified via the 2-item Maslach Burnout Inventory (MBI) and the Patient Health Questionaire-2 (PHQ-2), respectively. Residents then qualified their preferences for various assistance services and for the role of their program directors in assisting them.

RESULTS: One-hundred sixty-one of 202 (79.7\%) residents completed the survey. The rate of depression was $28 \%$. Rates of emotional exhaustion and depersonalization (2-item MBI) were 44 and $62 \%$, respectively. Only 4\% of respondents had used the Employee Assistance Program (EAP) in the prior 12 months. Eighty-two percent of residents were in favor of PDs inquiring about wellness regardless of their job performance and only $1 \%$ of residents stated the PD should not inquire about wellness at all. Thirty-three percent of residents reported that they would be likely to contact EAP on their own if they felt unwell. Significantly more residents (62\%) reported being more likely to contact EAP if recommended by their PD (33 vs $62 \%, p<0.001 \%$ ). Important perceived barriers to seeking assistance were lack of time $(65 \%)$, lack of knowledge of how to contact EAP (41\%), and concerns about appearing weak (35\%).

CONCLUSIONS: Despite a high prevalence of burnout and depression, residents are unlikely to seek help on their own. Program directors have an important role in assessing and promoting the wellness of their residents. The majority of residents wants their PD to inquire about wellness and may be more likely to seek and receive help if recommended and facilitated by their PD.

Received March 30, 2017

Revised November 17, 2017

Accepted February 1, 2018

Published online March 5, 2018
KEY WORDS: wellness; burnout; depression; resident; physician.

J Gen Intern Med 33(5):705-9

DOI: $10.1007 / \mathrm{s} 11606-018-4367-0$

(C) Society of General Internal Medicine 2018

\section{INTRODUCTION}

Burnout is a syndrome of exhaustion, cynicism, and decreased effectiveness at work. Current estimates suggest that the prevalence of burnout among practicing physicians in the USA exceeds $50 \% .^{1}$ Burnout is more prevalent among resident physicians than among medical students, or other agematched physicians and ranges from 40 to $80 \%$, depending on specialty. ${ }^{2}$ The prevalence of depression or depressive symptoms among resident physicians is estimated to be at least 28\%. ${ }^{3}$ The Accreditation Council for Graduate Medical Education (ACGME) has made resident wellness a top priority ${ }^{4}$ and requires that all program directors "mitigate excessive service demands and fatigue". Work hours restrictions and a variety of existing resident assistance programs have shown some benefits. ${ }^{6-17}$ Despite national awareness of the importance of resident well-being and the increasing availability of assistance programs, the problems of resident burnout and depression remain significant issues. ${ }^{18}$ The PD is in an ideal position to identify residents who are unwell, to refer to appropriate resources, and to protect the time for residents to get needed help. However, it has been shown that PDs may not accurately identify burnout and that residents may fear negative repercussions of PD involvement. ${ }^{19,} 20$ This study examines resident preferences for the residency program director's role in assessing and promoting their wellness. Specifically, we sought to understand how residents think program directors should identify burnout and depression, and how best to assist them in utilizing available resources.

\section{METHODS}

\section{Participants}

A total of 202 residents at the Greenville Health System (GHS) enrolled in eight residency programs (internal medicine, pediatrics, medicine-pediatrics, family medicine, psychiatry, ob-gyn, general surgery, and orthopedic surgery) were 
surveyed. Greenville Memorial Hospital is a 759 bed general medical and surgical facility and serves as the main clinical site for the residency programs as well as the University of South Carolina School of Medicine Greenville. The main resource for wellness at GHS is a free Employee Assistance Program (EAP) available to all residents.

\section{Data Collection}

Two-hundred two residents received a 21-question Survey Monkey questionnaire via email on January 26, 2017. Two subsequent email reminders were sent on February 2 and February 14 and the survey was closed February 17, 2017. There were no incentives offered for survey completion. To screen this population of residents for depression, we used the 2-question Patient Health Questionnaire (PHQ-2) instrument with the questions "Over the past two weeks, have you been bothered by any of the following problems: 'Little Interest or pleasure in doing things' and 'Feeling down, depressed or hopeless'?" The sensitivity and specificity for a score of 2 on the PHQ-2 for diagnosing major depression are 86 and $78 \%{ }^{21}$ To screen this population for burnout, we used two single items from the full Maslach Burnout Inventory (MBI) ${ }^{22}$ "I feel burned out from my work" and "I have become more callous toward people since I took this job." Responses of "A few times a week" to the single item measures of emotional exhaustion and depersonalization have demonstrated a stratified risk of high burnout in the relevant domains on the full $\mathrm{MBI}^{23}$

In order to protect the anonymity of respondents, we categorized residency types into "Technical" (general surgery, orthopedic surgery, and ob-gyn) and "Non-Technical" (internal medicine, pediatrics, medicine-pediatrics, family medicine, and psychiatry) categories. We gathered data on age and gender and also classified respondents into either PGY-1 or PGY-2 and above. Residents were then asked additional questions about available resources and their program director's role in assessing and promoting resident wellness.

A final free text question asked "Are there any other resources that GHS could provide to help with resident wellness?" Responses to this question were collated according to topic. Repeat topics were grouped and compared as a percentage of overall responses to this question. The study was given expedited approval without the need for informed consent by the Greenville Health System Institutional Review Board on January 13, 2017 (IRB File \# Pro000061276).

\section{Statistical Analysis}

Discrete variables are reported as $\mathrm{N}(\%)$ and differences between comparative groups were tested using Pearson's chisquare test or Fisher's exact test for small sample sizes $(n<5)$. Continuous variables are reported as the mean \pm standard deviation and differences between comparative groups were tested using Student's $t$ test. Values of $p$ less than 0.05 were considered statistically significant. All analyses were carried
Table 1 Demographics

\begin{tabular}{lr}
\hline \hline$N$ & 161 \\
Residency type, $N(\%)$ & $66(40.99)$ \\
Technical & $95(59.01)$ \\
Non-technical & \\
Year of training, $N(\%)$ & $44(27.33)$ \\
PGY 1 & $117(72.67)$ \\
PGY2+ & $83(51.55)$ \\
Gender, $N(\%)$ & $78(48.45)$ \\
Male & $29.6 \pm 2.9$ \\
Female & $119(73.91)$ \\
Age, mean \pm SD & $42(26.09)$ \\
$26-30, N(\%)$ & $116(72.05)$ \\
$31+, N(\%)$ & $45(27.95)$ \\
PHQ-2, $N(\%)$ & \\
$<2$ & $91(56.52)$ \\
$2+$ & $70(43.48)$ \\
Emotional exhaustion, $N(\%)$ & \\
Weekly or less & $85(52.8)$ \\
More than once weekly & $75(46.58)$ \\
Depersonalization, $N(\%)$ & \\
Weekly or less & \\
More than once weekly & \\
\hline
\end{tabular}

out using R statistical software (R Foundation for Statistical Computing, version 3.2.3, Vienna, Austria).

\section{RESULTS}

After the 3-week survey period, 161 of 202 residents had taken the survey for an overall response rate of $79.7 \%$. This response rate was similar across all demographics, including residency type, gender, and year of training (Table 1).

The overall rate of depression as determined by a PHQ-2 score of 2 or above in our sample was $28 \%(45 / 161)$. The overall rate of emotional exhaustion (single-item MBI weekly or more) was $44 \%(71 / 161)$ and the rate of depersonalization (single item MBI weekly or more) was $62 \%$ (100/161) (Table 2). Female residents were more likely than male to have a PHQ-2 above 2 (62 vs 38\%, $p=0.045$ ). A higher proportion of residents aged 26-30 reported emotional exhaustion than residents aged $31+(84$ vs $16 \% p=0.01)$ (Table 2).

When asked the question "If you felt unwell, would you contact the Employee Assistance Program (EAP) on your own?" Thirty-two percent of all respondents said "Yes." When asked the follow-up question "If you felt unwell would you be more likely to contact the EAP if your Program Director recommended it, 63\% responded "Yes." The difference in responses between these items was statistically significant $(p<0.001)$.

Only $4 \%$ of all respondents (7/161) reported having used the EAP within the past 12 months. When asked "Did you find the EAP helpful?" all 7 who used the EPA responded "Yes." When asked "Which of the following might prevent you from using the EAP?" the items receiving the most responses were "I do not have time" 64\% (95/149 responses) and "I don't know how to contact the EAP" $41 \%$ (61/149 responses).

When asked "What does your program director do to assess your wellness?" 55\% responded "Informally inquire about 
Table 2 Results

\begin{tabular}{|c|c|c|c|c|c|c|c|c|c|}
\hline & \multicolumn{3}{|l|}{ PHQ-2 } & \multicolumn{3}{|c|}{ Emotional exhaustion } & \multicolumn{3}{|c|}{ Depersonalization } \\
\hline & $<2$ & $2+$ & $\begin{array}{l}P \\
\text { value }\end{array}$ & $\begin{array}{l}\text { Less than } \\
\text { weekly }\end{array}$ & $\begin{array}{l}\text { Weekly or } \\
\text { more }\end{array}$ & $\begin{array}{l}P \\
\text { value }\end{array}$ & $\begin{array}{l}\text { Less than } \\
\text { weekly }\end{array}$ & $\begin{array}{l}\text { Weekly or } \\
\text { more }\end{array}$ & $\begin{array}{l}P \\
\text { value }\end{array}$ \\
\hline $\mathrm{N}$ & 116 & 45 & \multirow{4}{*}{0.293} & 91 & 70 & \multirow{3}{*}{1.000} & 85 & 76 & \multirow{4}{*}{0.283} \\
\hline Residency type, $N(\%)$ & & & & & & & & & \\
\hline Technical & $\begin{array}{l}51 \\
(43.97)\end{array}$ & $\begin{array}{l}15 \\
(33.33)\end{array}$ & & 37 (40.66) & $29(41.43)$ & & $31(36.47)$ & $35(46.05)$ & \\
\hline Non-technical & $\begin{array}{l}65 \\
(56.03)\end{array}$ & $\begin{array}{l}30 \\
(66.67)\end{array}$ & & $54(59.34)$ & $41(58.57)$ & & $54(63.53)$ & $41(53.95)$ & \\
\hline Year of training, $\mathrm{N}(\%)$ & & & \multirow[t]{3}{*}{1.000} & & & 0.398 & & & \multirow[t]{2}{*}{0.769} \\
\hline PGY 1 & $\begin{array}{l}32 \\
(27.59)\end{array}$ & $\begin{array}{l}12 \\
(26.67)\end{array}$ & & $22(24.18)$ & $22(31.43)$ & & $22(25.88)$ & $22(28.95)$ & \\
\hline PGY2+ & $\begin{array}{l}84 \\
(72.41)\end{array}$ & $\begin{array}{l}33 \\
(73.33)\end{array}$ & & $69(75.82)$ & $48(68.57)$ & & $63(74.12)$ & $54(71.05)$ & \multirow{4}{*}{0.830} \\
\hline Gender, $N(\%)$ & & & \multirow[t]{3}{*}{0.045} & & & 0.145 & & & \\
\hline Male & $\begin{array}{l}66 \\
(56.90)\end{array}$ & $\begin{array}{l}17 \\
(37.78)\end{array}$ & & $52(57.14)$ & $31(44.29)$ & & $45(52.94)$ & $38(50.00)$ & \\
\hline Female & $\begin{array}{l}50 \\
(43.10)\end{array}$ & $\begin{array}{l}28 \\
(62.22)\end{array}$ & & $39(42.86)$ & $39(55.71)$ & & $40(47.06)$ & $38(50.00)$ & \\
\hline Age, mean $\pm \mathrm{SD}$ & $\begin{array}{l}29.8 \pm \\
3.1\end{array}$ & $\begin{array}{l}29.1 \pm \\
2.1\end{array}$ & 0.103 & $28.9 \pm 2.0$ & $30.2 \pm 3.3$ & 0.003 & $30.1 \pm 3.4$ & $29.1 \pm 2.0$ & 0.026 \\
\hline $26-30, N(\%)$ & $\begin{array}{l}111 \\
(95.69)\end{array}$ & $\begin{array}{l}8 \\
(17.78)\end{array}$ & 1.000 & $60(65.93)$ & $59(84.29)$ & 0.011 & $58(68.24)$ & $61(80.26)$ & 0.120 \\
\hline $31+, N(\%)$ & $\begin{array}{l}40 \\
(34.48)\end{array}$ & $2(4.44)$ & & $31(34.07)$ & $11(15.71)$ & & $27(31.76)$ & $15(19.74)$ & \\
\hline $\begin{array}{l}\text { More likely to use EAP if PD } \\
\text { recommends, } N(\%)\end{array}$ & $\begin{array}{l}74 \\
(63.79)\end{array}$ & $\begin{array}{l}28 \\
(62.22)\end{array}$ & 0.997 & $61(67.03)$ & $41(58.57)$ & 0.347 & $56(65.88)$ & $46(60.53)$ & 0.589 \\
\hline $\begin{array}{l}\text { Used EAP in the last } 12 \\
\text { months, } N(\%)\end{array}$ & $3(2.59)$ & $4(8.89)$ & 0.060 & $2(2.20)$ & $5(7.14)$ & 0.034 & $2(2.35)$ & $5(6.58)$ & 0.087 \\
\hline \multicolumn{10}{|c|}{ How likely to use the following, $N(\%)$} \\
\hline EAP & $\begin{array}{l}24 \\
(20.69)\end{array}$ & $\begin{array}{l}11 \\
(24.44)\end{array}$ & 0.670 & $19(20.88)$ & $16(22.86)$ & 0.946 & $20(23.53)$ & $15(19.74)$ & 0.644 \\
\hline Health care provider & $\begin{array}{l}57 \\
(49.14)\end{array}$ & $\begin{array}{l}20 \\
(44.44)\end{array}$ & 0.856 & $50(54.95)$ & $27(38.57)$ & 0.052 & $49(57.65)$ & $28(36.84)$ & 0.010 \\
\hline Program director & $\begin{array}{l}51 \\
(43.97)\end{array}$ & $\begin{array}{l}16 \\
(35.56)\end{array}$ & 0.468 & $42(46.15)$ & $25(35.71)$ & 0.232 & $35(41.18)$ & $32(42.11)$ & 1.000 \\
\hline Colleagues & $\begin{array}{l}80 \\
(68.97)\end{array}$ & $\begin{array}{l}26 \\
(57.78)\end{array}$ & 0.178 & $64(70.33)$ & $42(60.00)$ & 0.204 & $57(67.06)$ & $49(64.47)$ & 0.795 \\
\hline Family & $\begin{array}{l}97 \\
(83.62)\end{array}$ & $\begin{array}{l}37 \\
(82.22)\end{array}$ & 0.795 & $78(85.71)$ & $56(80.00)$ & 0.653 & $71(83.53)$ & $63(82.89)$ & 1.000 \\
\hline Church/spiritual & $\begin{array}{l}70 \\
(60.34)\end{array}$ & $\begin{array}{l}14 \\
(31.11)\end{array}$ & 0.002 & $53(58.24)$ & $31(44.29)$ & 0.100 & $49(57.65)$ & $35(46.05)$ & 0.162 \\
\hline Exercise & $\begin{array}{l}98 \\
(84.48)\end{array}$ & $\begin{array}{l}27 \\
(60.00)\end{array}$ & 0.001 & $75(82.42)$ & $50(71.43)$ & 0.106 & $70(82.35)$ & $55(72.37)$ & 0.121 \\
\hline
\end{tabular}

wellness at semi-annual review" and 20\% reported "Formally screen for depression and burnout at semi-annual review. Twelve percent reported that they inquire only if there is a work-performance issue and $9 \%$ stated they do not inquire. When asked the follow-up question "How should your program director assess your wellness?" $51 \%$ reported that they should informally inquire and $31 \%$ preferred formal screening at the semi-annual review. Ten percent stated that they should only inquire if there are job performance issues. Only $1 \%$ of residents reported that the program director should not inquire at all.

When asked about comfort with openly discussing wellness with your program director, $66 \%$ reported that they would feel comfortable. When asked about factors that might prevent them from discussing wellness with the PD, 35\% were afraid to look weak, and $28 \%$ worried about it negatively affecting career goals.

When asked to compare how likely they would be to utilize various resources to improve overall wellness, $88 \%$ listed family, $82 \%$ listed exercise, and $69 \%$ listed colleagues. Fifty percent listed health care provider, $44 \%$ listed the PD, and
$23 \%$ reported being likely to use the EAP (Table 3 ). Residents with a positive depression screen were significantly less likely to list church/spiritual activities (31 vs 60\%, $p=0.002$ ) or exercise (60 vs $84 \%, p=0.001$ ) as an outlet for wellness than those residents who were not depressed. Residents experiencing depersonalization were also significantly less likely to list utilizing a PCP for wellness than those residents who were not (37 vs $58 \%, p=0.01$ ) (Table 2 ).

Table 3 Would You Use the Following to Improve Health

\begin{tabular}{lrr}
\hline \hline & Yes & No \\
\hline Family & $134(87.58)$ & $20(13.07)$ \\
Exercise & $125(81.7)$ & $29(18.95)$ \\
Colleagues & $106(69.28)$ & $48(31.37)$ \\
Church/spiritual & $84(54.9)$ & $70(45.75)$ \\
Health care prof. & $77(50.33)$ & $75(49.02)$ \\
Program director & $67(43.79)$ & $87(56.86)$ \\
EAP & $35(22.88)$ & $118(77.12)$ \\
\hline
\end{tabular}

Note percentages do not add up to 100 because there were some skipped responses 
A final free text question asked "Are there any other resources that GHS could provide to help with resident wellness?" 33 residents responded to this question, and $45 \%$ (15/33) mentioned a need for space for exercise within the hospital. Other responses included the structured time outside of PTO for life personal activities such as doctor visits and home/car maintenance appointments.

\section{DISCUSSION}

Our overall response rate was very robust, with almost $80 \%$ of all residents completing the survey without any additional incentive to do so. The high response rate suggests that this is an important issue among the residents. The prevalence of symptoms of emotional exhaustion, depersonalization, and depression in our cohort are consistent with national data. ${ }^{1-3}$ Despite the high prevalence of symptoms for burnout and depression, and that $80 \%$ of residents were routinely asked about wellness by their PDs, it was striking that only $4 \%$ of our cohort had actually utilized our Employee Assistance Program (EAP) in the past 12 months. All of the individuals who actually used the EAP in the last year found it to be helpful. Several important questions arise regarding this disconnect.

First, it is possible that informal screening techniques used by program directors may not identify the full extent of depression or burnout in their residents. Fifty-five percent of inquiries about wellness were described as "informal" by the residents. It has been noted elsewhere that PDs are unable to identify burnout accurately. ${ }^{19}$ It is possible that the use of more formal screening tools may help identify at risk residents. Whether residents who test positive on a formal screen for burnout or depression would be more likely to seek help than those screened informally is a question for further study. Residents did report being more likely to use the EAP if their PD recommended it, but it is not clear that this would actually be the case. Only $4 \%$ of our cohort had actually contacted the EAP in the past 12 months, despite $80 \%$ of PDs routinely inquiring. Perhaps a more directive statement from the PD about the need for and potential benefits of assistance may make an impact, but this is a question for further investigation.

It may also be possible that residents are seeking formal or informal help outside of the EAP. While we asked about general preferences for a variety of resources for improving wellness, we did not inquire about the specific use of other resources in the past 12 months. When asked to rank resources they would be likely to use, it was interesting to note that the majority of residents preferred more social avenues-family, exercise, colleagues, and church activities compared to work-related resources such as a health care provider, the PD, or the EAP (Table 3). There is evidence supporting the efficacy of a variety of individual-driven interventions including mindfulness, meditation, and self-care ${ }^{9,10,24,25}$ and exercise. ${ }^{26}$ Protecting time and making these more widely available to residents may provide benefit. ${ }^{27}$ When asked about factors that might prevent them from discussing wellness with the PD, about a third were afraid to look weak and worried about it negatively affecting career goals. This concern is consistent with other studies as well that show doctors are unlikely to seek self-help for fear of stigmatization. ${ }^{27}$ Holmes et al. showed that up to $25 \%$ of residents erroneously believed that burnout was reportable to the medical board. ${ }^{19}$ Clarifying rules of confidentiality for residents seeking help may help to foster more open communication around wellness, but this is a question for further study as well. Program directors could also consider developing peer or faculty mentors with a vested interest in resident wellness to help identify and direct residents to appropriate resources. Involving other faculty might remove the fear of stigmatization by the PD. Formal wellness and coaching programs have been developed with success elsewhere. ${ }^{12-16}$

The other significant barrier residents identified in seeking help were having the time to do so and understanding what services were available to them. Other studies have demonstrated lack of time as a significant, persistent barrier. ${ }^{20,28} \mathrm{PDs}$ can directly address these barriers by actively informing residents about resources such as EAP, and also specifically protecting time for them to receive services. It is important to do this in a way that protects confidentiality and reduces a fear of repercussions.

Female residents in our population were at increased risk for depression. Other studies have shown that emotional distress and depression are more prevalent among female residents and medical students. ${ }^{28}$ Residents reporting engagement in spiritual activities were less likely to be depressed compared to those who did not. A protective effect of spirituality has been found in other studies of resident depression and burnout. ${ }^{29,30}$ Depressed residents were also less likely to report using exercise as a method of coping with stress than those who were not depressed. Exercise has been inversely associated with exhaustion in other studies. ${ }^{26}$ Younger residents (aged 26-30) were at increased risk for emotional exhaustion compared to older ones $>30$. Woodside et $\mathrm{al}^{31}$ evaluated the association between age and burnout, and showed an inverse correlation between depersonalization scores and age of family medicine and psychiatry residents. However, other studies have not consistently demonstrated correlation between age and burnout. $^{32}$ There were no significant differences in rates of burnout or depression between technical and non-technical residents in our population, which is also consistent with previous studies. $^{33,34}$

There were some limitations to our study. This was a crosssectional survey that did not measure the impact of any interventions offered. The Greenville Health System is a clinical university model with a medical school in a community setting and may not be generalizable to larger academic medical centers. We also used short form scales for both burn out and depression (2-item MBI and PHQ-2) for ease of use for a busy 
resident population, which have good sensitivity but somewhat reduced specificity compared to the long forms, and might overestimate depression and burnout symptoms. ${ }^{21,23}$

\section{CONCLUSION}

Despite a high prevalence of burnout and depression, residents are unlikely to seek help on their own. The majority of residents wants their PD to inquire about wellness and may be more likely to seek and receive help if recommended and facilitated by their PD. PDs are uniquely positioned to identify, refer, and protect the time of residents who are at risk for being unwell. Further study is needed into the best ways for PDs to do this in a supportive, confidential, and effective manner. As one resident in our study commented, "Most of us are excited about our careers and taking care of patients. Giving us support and listening to the things that make our lives unnecessarily difficult would be a good start."

Corresponding Author: Russ C. Kolarik, MD; University of South Carolina Greenville, Greenville, SC, USA (e-mail: rkolarik@ghs.org).

\section{Compliance with Ethical Standards:}

Conflict of Interest: The authors declare no conflict of interest.

Abbreviations ACGME, Accreditation Council on Graduate Medical Education; GHS, Greenville Health System; EAP, Employee Assistance Program; PHQ-2, 2-Question Patient Health Questionnaire; $M B I$, Maslach Burnout Inventory; $P D$, program director; PGY, post graduate year

\section{REFERENCES}

1. Shanafelt TD, Hasan O, Dyrbye LN, et al. Changes in burnout and satisfaction with work-life balance in physicians and the general US working population between 2011 and 2014. Mayo Clin Proc. 2015;90(12):1600-1613..

2. Dyrbye LN, West CP, Satele D, et al. Burnout among US medical students, residents, and early career physicians relative to the general US population. Acad Med. 2014;89(3):443-451

3. Prins JT, Gasendam-DOnofrio SM, Tubben BJ et al. Burnout in medical residents: a review. Me Educ. 2007; 41(8): 788-800.

4. Accreditation Council for Graduate Medical Education. ACGME Physician Well-being Initiative: http://www.acgme.org/What-We-Do/Initiatives/Physician-Well-Being/Education. Accessed January 16, 2018.

5. Accreditation Council for Graduate Medical Education. Common Program Requirements. Section II.A.4.j).(3). http://www.acgme.org/WhatWe-Do/Accreditation/Common-Program-Requirements Accessed January 16,2018 .

6. Goitein L, Shanafelt TD, Wipf JE, et al. The effects of work-hour limitations on resident well-being, patient care, and education in an internal medicine residency program. Arch Intern Med. 2005;165(22):2601-2606.

7. Gopal R, Glasheen JJ, Miyoshi TJ, et al. Burnout and internal medicine resident work-hour restrictions. Arch Intern Med. 2005; 165(22):2595-2600.

8. Hutter MM, Kellogg KC, Ferguson CM, et al. The impact of the 80-hour resident workweek on surgical residents and attending surgeons. Ann Surg. 2006;243(6):864-871; discussion 871-865

9. Martins AE, Davenport MC, Del Valle MP, et al. Impact of a brief intervention on the burnout levels of pediatric residents. J Pediatr (Rio J). 2011;87(6):493-498.

10. Ospina-Kammerer V, Figley CR. An evaluation of the Respiratory One Method (ROM) in reducing emotional exhaustion among family physician residents. Int J Emerg Ment Health. 2003;5(1):29-32.
11. Levey RE. Sources of stress for residents and recommendations for programs to assist them. Acad Med. 2001;76(2):142-50.

12. Palamara K, Kauffman $\mathbf{C}$, Stone $\mathbf{V}$ et al. Promoting Success: A professional development coaching program for interns in medicine. JGME. 2015:630-637.

13. Ey S, Moffit M, Kinizie JM et al. "If you build it they will come : attitudes of medical residents and fellows about seeking services in a resident wellness program." J Grad Med Educ. 2013;5(3):486-492.

14. Watson DT, Long WJ, Yen D, et al. Health promotion program: a resident well-being study. Iowa Orthop J. 2009;29:83-87.

15. Foster E, Biery N, Dostal J, et al. Supporting resident well-being through an integrated advising and assessment process. Fam Med. 2012; 44(10):731-734

16. Sadaat $\mathbf{H}$, Snow DL, Ottenheimer $\mathbf{S}$ et al. Wellness program for anesthesiology residents: a randomized controlled trial. Acat Anaesthesiol Snad. 2012;56:141-166.

17. Busireddy KR, Miller JA, Ellison $\mathbf{K}$, et al. Efficacy of interventions to reduce resident physician burnout: a systematic review. J Grad Med Educ. 2017;9(3):294-301.

18. Kristin S. Raj. Well-Being in Residency: A Systematic Review. Journal of Graduate Medical Education: December 2016, Vol. 8, No. 5, pp. 674-684

19. Holmes EG, Connolly A, Putnam KT, Penaskovic KM, Denniston CR, Clark LH, Rubinow DR, Meltzer-Brody S. Taking Care of Our Own: A Multispecialty Study of Resident and Program Director Perspectives on Contributors to Burnout and Potential Interventions. Acad Psychiatry. 2017 Apr;41(2):159-166.

20. Constance Guille, Heather Speller, Rachel Laff, C. Neill Epperson, and Srijan Sen. Utilization and barriers to mental health services among depressed medical interns: a prospective multisite study. Journal of Graduate Medical Education 2010 2:(2), 210-214.

21. Arroll B, Goodyear-Smith F, Crengle S, et al. Validation of PHQ-2 and PHQ-9 to Screen for Major Depression in the Primary Care Population. Annals of Family Medicine. 2010;8(4):348-353.

22. Maslach C, Jackson SE, Leiter MP. Maslach Burnout Inventory Manual. 3rd ed. Palo Alto, CA: Consulting Psychologists Press; 1996.

23. West CP, Dyrbye LN, Sloan JA, Shanafelt TD. Single Item Measures of Emotional Exhaustion and Depersonalization Are Useful for Assessing Burnout in Medical Professionals. Journal of General Internal Medicine. 2009;24(12):1318-1321.

24. Shapiro S., Astin J., Bishop S., Cordova M. Mindfulness-based stress reduction for health care professionals: results from a randomized trial. Int J Stress Manage. 2005;12(2):164-176.

25. Galantino M. L., Baime M., Maguire M., Szapary P. O., Farrar J. T. Short communication: in association of psychological and physiological measures of stress in health-care professionals during an 8-week mindfulness meditation program. Stress Health. 2005;21(4):255-261.

26. Naczenski LM, de Vries JD, van Hooff MLM, Kompier MAJ. Systematic Review of the Association between Physical Activity and Burnout. J Occup Health. 2017.

27. Adams EF, Lee AJ, Pritchard CW, white RJ. What stops us from healing the healers: a survey of help-seeking behaviour, stigmatisation and depression within the medical profession. Int $\mathrm{J}$ Soc Psychiatry. 2010;56(4):359-70.

28. IsHak, Waguih William et al. Burnout During Residency Training: A Literature Review. Journal of Graduate Medical Education 1.2 (2009): 236-242. PMC. Web. 6 Nov. 2017.

29. Yi MS, Luckhaupt SE, Mrus JM, Mueller CV, Peterman AH, Puchalski CM, Tsevat J. Religion, spirituality, and depressive symptoms in primary care house officers. Ambul Pediatr. 2006; 6(2):84-90.

30. Benjamin R. Doolittle, Donna M. Windish, Charles B. Seelig. Burnout, Coping, and Spirituality Among Internal Medicine Resident Physicians. J Grad Med Educ. 2013; 5(2): 257-261. https://doi.org/10.4300/JGMED-12-00136.1

31. Woodside JR, Miller MN, Floyd MR, McGowen KR, Pfortmiller DT. Observations on burnout in family medicine and psychiatry residents. Acad Psychiatry. 2008; 32(1):13-9.

32. Lemkau JP, Purdy RR, Rafferty JP, Rudisill JR. Correlates of burnout among family practice residents. J Med Educ. 1988; 63(9):682-91.

33. Martini S, Arfken CL, Churchill A, et al. Burnout comparison among residents in different medical specialties. Acad Psychiatry. 2004;28(3):240-242

34. Dyrbye LN, Thomas MR, Shanafelt TD. Systematic review of depression, anxiety, and other indicators of psychological distress among U.S. and Canadian medical students. Acad Med. 2006:81(4):354-73. 